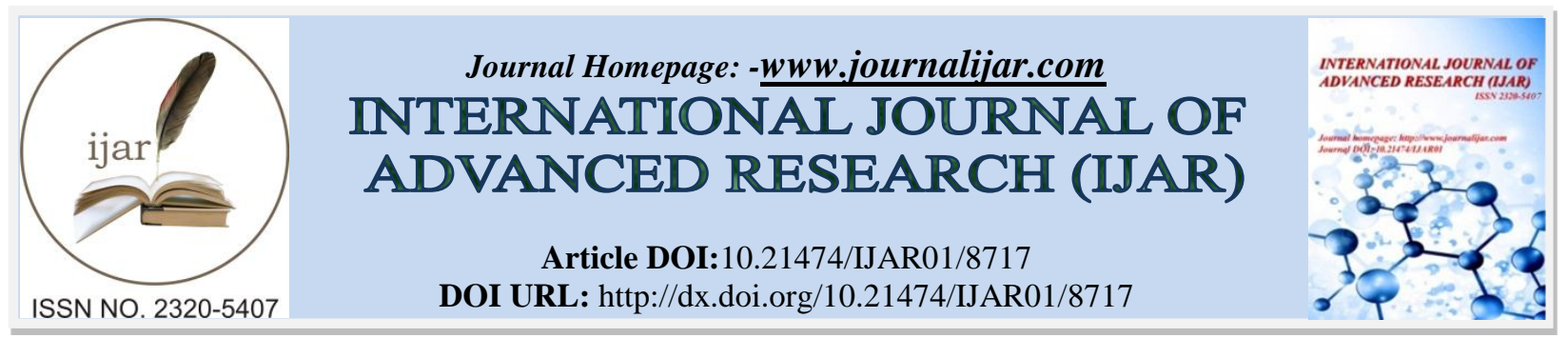

RESEARCH ARTICLE

\title{
MID FOREARM ANEURYSM ASSOCIATED WITH BLUNT TRAUMA - A CASE REPORT \& LITERATURE REVIEW.
}

\section{Arockia Sundari J J, Pinjala Ramakrishna, Naren Shetty, Gnaneshwar Atturu, Sandeep Mahapatra and Nihar Ranjan Pradhan.}

\section{Manuscript Info}

\section{Abstract}

\section{Manuscript History}

Received: 17 January 2019

Final Accepted: 19 February 2019

Published: March 2019

\section{Keyword}

radial artery and aneurysm.

Copy Right, IJAR, 2019,. All rights reserved.

\section{Introduction:-}

True radial artery aneurysms are rare with majority of aneurysms being pseudoaneurysms. True radial artery aneurysm secondary to blunt injury are even rarer. A case of true radial artery aneurysm presenting after blunt injury is presented here with review of literature.

\section{Case Report}

A 18 years old male presented with a pulsatile mass at his right forearm. The swelling was preceded by fall and trauma to forearm three months back. There was no associated bony injury and no significant past medical history. physical examination revealed a single pulsatile, nontender swelling over the mid forearm with distal palpable pulses with no neurological deficits. skin over the swelling was normal. Other systemic examination was negative for connective tissue disorders.

Doppler arterial ultrasound of the right forearm showed heterogenous pulsatile focal lesion of right radial artery with partial thrombosis. Rest of radial artery was normal.

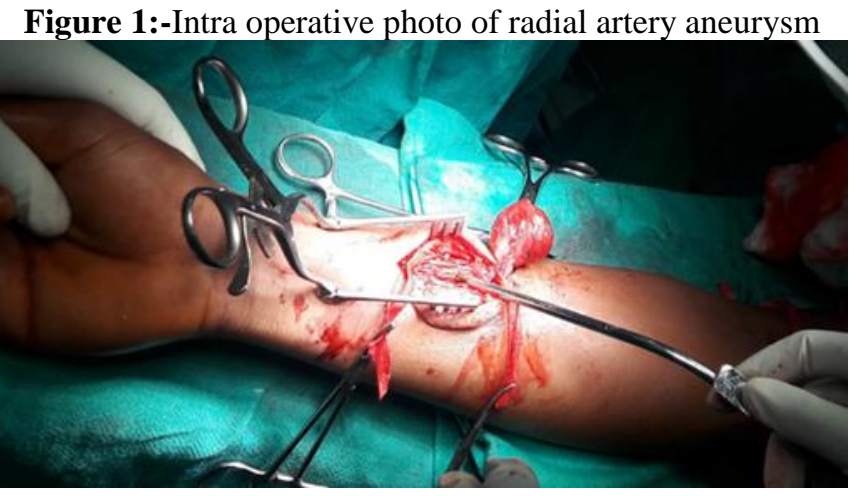


Under axillary nerve block, the swelling was resected. The proximal and distal ends were ligated after confirming the distal forearm and hand perfusion. histopathology specimen showed a saccular aneurysm of $2.3 \mathrm{~cm}$, with inflammatory infiltrates in all layers of arterial wall.

Figure 2:-histology of radial artery aneurysm

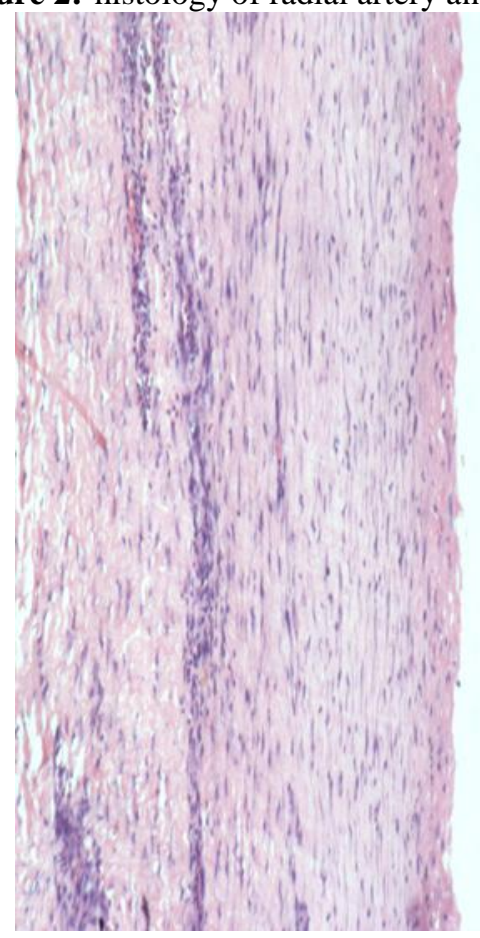

\section{Literature review:}

Pubmed, Embase and Ovid databases, from 1940 to 2019, were searched. 298 papers were retrieved and less than 92 papers were relevant to true radial artery aneurysm.

\section{Discussion:-}

Radial artery aneurysms are $2.9 \%$ of all peripheral aneurysms reported of the $1 \%$ of upper limbs aneurysms ${ }^{1,2}$, with less than 25 cases of traumatic 'true' aneurysms ${ }^{3}$. Iatrogenic, autoimmune, arterio venous fistula creation, trauma with bony injury, occupational injury were the commonly reported causes.

The common clinical presentation is pain and signs of ischemia, caused by thrombosis or distal microembolization from true radial artery aneurysms. In the case described here, there was no complaint of ischemia, compressive sensory or motor symptoms, gangrene, or rupture and modified allen's test was negative.

The diagnosis was by clinical examination, and the imaging modality was used to confirm the plan of management of the aneurysm. Duplex ultrasonography with colour doppler was used to differentiate the aneurysm from other vascular swellings and fistulas. The decision of excision with ligation of radial artery was based on adequacy of perfusion of hand and patency of ipsilateral ulnar artery.

Conclusion: Traumatic radial artery aneurysms can develop because of endothelial damage and compression due to blunt trauma. Intervention is needed to prevent undue complications of distal limb. Excision of aneurysm and arterial ligation, was the preferred treatment in this case. 


\section{References:-}

1. Naiem Nassiri*, Samuel Kogan, Huong Truong, KJ Nagarsheth, Randy Shafritz and Saum Rahimi. Surgical Repair of a Snuffbox Radial Artery Pseudoaneurysm. Clinics in Surgery. oct 2016; 1: 1154

2. Amir A. Ghaffarian, MD, Benjamin S. Brooke, MD, PhD, Jay Rawles, MD, Mark Sarfati, MD . Repair of a symptomatic true radial artery aneurysm at the anatomic snuff box with interposition great saphenous vein graft. J Vasc surg cases Innov Tech. Dec $2018 ; 4: 4$.

3. 3. Thai $\mathrm{H}^{*}$, Vasyluk A, Rits Y. Bilateral Radial Artery Aneurysm: Case Report and Review of Literature. J Vasc Med Surg. Jan 2016; 4:247. 